\title{
Culture, strategic alliances, mergers and acquisitions: an introduction
}

\section{Elise Meijer, Geert Duysters and Jan Ulijn}

Over the past decades, we have witnessed a sharp upheaval in the number of external organizational modes such as strategic alliances and mergers and acquisitions (M\&A). ${ }^{1} \mathrm{~A}$ large strand of literature has already reported on the benefits of these modes, for example the sharing of costs and risks, the learning of new skills and technologies and their role in international efforts of companies. In spite of the noted benefits, however, the track record of these external organizational modes paints a black picture. Most studies show that more than half of the strategic alliances and M\&A do not prove to be successful.

Traditionally, scholars focused on 'hard' factors like financial and strategic factors for explaining the success or failure of these external modes. More recently, however, research into more 'soft' factors such as organizational and human resources-linked subjects have increased in importance (Larsson and Finkelstein, 1999; Stahl and Voigt, 2008). This has led to a growing and emergent body of literature on the importance of culture for the success of strategic alliances and M\&A. ${ }^{2}$ According to Hofstede (2001), culture can be treated as 'the collective programming of the mind that distinguishes the members of one group or category of people from another' (p. 9). As argued by among others Stahl and Voigt (2008), scholars have sought to explain the (under)performance of these external modes by variables such as cultural distance (Morosini et al., 1998; Simonin, 1999; Shenkar, 2001), cultural diversity (Parkhe, 1991), cultural compatibility (Cartwright and Cooper, 1996; Sarkar et al., 2001), cultural fit (Datta and Puia, 1995; Child and Faulkner, 1998; Weber et al., 1996), management style similarity (Larsson and Finkelstein, 1999), organization (cultural) congruence (Brown et al., 1988; Barkema et al., 1996; Park and Ungson, 1997), cultural change (Kavanagh and Ashkanasy, 2006), cultural convergence (Birkinshaw et al., 2000), or acculturation (Nahavandi and Malekzadeh, 1988; Larsson and Lubatkin, 2001). ${ }^{3}$

Much of this research has investigated the impact of national culture on the performance or longevity of strategic alliances and M\&A. Different 
national cultures lead to extensive differences between the people who are part of the strategic alliance or merger and acquisition because they are subject to fundamentally different sets of social institutions, including education systems, labour markets and geographical mobility (Calori et al., 1997; Whitley, 1992; Hambrick et al., 2001). These differences in national culture can create a source of conflict and misunderstanding that prevents the partners from successful cooperation (for example Parkhe, 1991; Datta and Puia, 1995; Lyles and Salk, 1996). This is in line with Hofstede's (1980) hypothesis of cultural distance in which he argues that the difficulties, costs and risks associated with cross-cultural contact increase with growing cultural differences between individuals, groups or organizations (Stahl and Voigt, 2008). Barkema and Vermeulen (1997), for example, found that differences in uncertainty avoidance and long-term orientation between home and host country (rather than differences in power distance, individualism and masculinity) have a negative impact on international joint venture survival because these make organizations perceive the opportunities and threats differently, which may result in different actions by the organizations (Schneider and De Meyer, 1991). However, the opposite view, that differences in national culture between the partnering organizations can be beneficial, leading to a source of value creation and learning, has also been advanced and empirically supported (Shenkar and Zeira, 1992; Park and Ungson, 1997; Stahl and Voigt, 2008). Morosini et al. (1998), for example, found that national cultural distance enhances cross-border acquisition performance 'by providing access to the target's and/or the acquirer's diverse set of routines and repertoires embedded in national culture' (p. 137).

These inconclusive results of the effect of cultural differences on performance may imply that the role of national culture has been overstated: most studies have not taken into account the impact of organizational cultural differences as well (Pothukuchi et al., 2002; Sirmon and Lane, 2004). Pothukuchi et al. (2002) even found that the apparent negative effects of partner dissimilarity on international joint venture performance 'originates more from differences in organizational culture than from differences in national culture because organizational culture distance captures the ongoing operational differences in the norms of organizational practices and behaviors' (p. 259) negatively influencing the implementation of the joint venture. Whereas national culture is first and foremost related to inherent values, organizational culture primarily relates to common beliefs in organizational practices and processes (Hofstede et al., 1990). According to Hambrick et al. (2001) each parent firm will have its own internal culture, including management selection and staffing practices, giving way to a distinctly skewed set of managers who are responsible for the strategic alliance or M\&A. Research in strategic alliances and M\&A has consistently 
shown negative effects of organizational culture differences (Cartwright and Cooper, 1993; Pothukuchi et al., 2002). For instance, Weber et al. (1996) showed that differences in organizational cultures between acquirer and acquired firm negatively influenced cooperation among the top managers and enhanced negative attitudes toward the merger. Additionally, Simonin (1999) showed that differences in management styles and business practices amplify ambiguity in the process of knowledge transfer.

However, there is one cultural level out of the three generally distinguished that has often been overlooked and may also affect strategic alliances and M\&A, namely professional culture (Ulijn and Weggeman, 2001; Sirmon and Lane, 2004). According to Sirmon and Lane $(2004,311)$ a professional culture exists 'when a group of people employed in a functionally similar occupation share a set of norms, values and beliefs related to that occupation'. According to Lane and Lubatkin (1998) individuals with different occupational socialization and resulting professional culture lack a common basis from which to interact effectively and from which the relationship can develop and produce value. Therefore, it is not very suprising that Lajara et al. (2003) found that technology (research and development, R\&D) alliances are the alliances with the lowest level of cultural conflict, due to the fact that the habits of scientists and engineers are practically the same on a worldwide basis. Problems start to occur when the cooperation is extended to commercialization and distribution because people from different professional cultural backgrounds start working together who do not agree on certain points (Schultz, 1998). On the other hand, different mental models or different 'thought worlds' belonging to the different professions may facilitate the dynamic process of combining diverse competencies which boosts team collective creativity, leading to the successful development of new products (Olson et al., 1995).

So far, little attention has been paid to the level of professional culture in strategic alliances and M\&A. Most studies on the role of culture, strategic alliances and M\&A have focused on national and corporate culture. However, successful cooperation also requires that different professions of the partnering companies are able to interact with each other. Therefore the essence of our book is that both national and corporate culture as well as professional culture may affect the success of strategic alliances and M\&A (see also Sirmon and Lane, 2004). That is, individuals in strategic alliances and M\&A can utilize several different social identities (namely national, organizational and occupational) as sense-making mechanisms (see for example Salk and Shenkar (2001)).

Consequently, we will deal in this book with three different levels of culture, namely national culture, organizational (or corporate) culture and 
professional culture. Given the kaleidoscope of the influence of culture on strategic alliances and M\&A we had to adopt several guidelines for the order of the chapters in this book. First, the level of culture involved, from national to corporate to the broadly underestimated professional culture. Second, being mostly a mix of different levels of culture, the chapters are also presented in an order going from rather conceptualizing with some illustrating case study examples, to rather empirical studies.

Chapter 1, 'Strategic alliances and culture in a globalizing world' by Kumar and Das examines how micro behavioural processes in alliances are affected by national culture. They discuss two significant frameworks of alliance functioning, namely, those of discrepancy and legitimacy, and argue that the impact of culture is manifested differently in the two frameworks. While the discrepancy framework stresses the importance of expectations, the legitimacy framework highlights the relevance of appropriate behaviour. Although expectations and behaviour are no doubt related, they are also quite distinct, and this distinction is important in understanding the genesis of the stability problems in an alliance.

Chapter 2, 'Why do international alliances fail? Some insights from culture and human social biology' by Hofstede combines alliance literature with basic insights from human social biology and culture to explain why international alliances frequently fail. In particular, the work of Hofstede is brought to bear upon the processes that occur in alliances. First, he argues that alliances often fail for many other reasons than culture. Hereafter a number of frameworks from the alliance literature are introduced. Kumar and Nti's framework about the evolution of discrepancies is the most important of these, as it can explain the dynamics of cross-cultural conflicts. The importance of alliance formation has been considered to be a basic ability of human groups. After this, Hofstede's framework of five basic issues of culture is introduced, and national culture is briefly positioned against professional and organizational culture. These various theories are integrated in a discussion about three boundaries that alliances have to cope with: the issues of authority, of joint group membership and of fairness. The insights from culture theory are used to elucidate how issues from the alliance literature can play out in different cross-cultural situations. Two case studies taken from the international agro-food sector illustrate the argument.

Chapter 3, 'Creating a supportive culture for corporate entrepreneurship: balancing creativity and discipline for the development of radical innovation by interfirm cooperation' by Walrave, Gilsing and De Jager, addresses the question of whether entrepreneurial corporate activities and/ or ventures are required to deviate from established practices that come with the dominant corporate culture. To answer this question they analyse 
the key features of culture of an organizational unit that specializes in corporate entrepreneurship (CE) activities, using Hofstede's dimensions of corporate culture. They illustrate this analysis with empirical findings on the culture of various $\mathrm{CE}$ units within two large, high-tech companies. Moreover they discuss how such a CE-'friendly' culture may be created. Here, they specifically discuss the role of strategic alliances as a means to accomplish a CE culture in such a way that it indeed differs in essential ways from the dominant parent culture.

In Chapter 4, 'Culture and its perception in strategic alliances: does it affect performance? An exploratory study into Dutch-German ventures', Ulijn, Duysters and Fèvre consider both national and corporate culture. This exploratory study examines the fit, that is, the degree of fruitful compatibility, of six national culture (NC) and six corporate culture (CC) (the dimensions of Hofstede) parameters in 12 Dutch-German cooperation processes. Twenty-four firms were asked to verify the nature of their cultural fit and to relate this perception to the perceived alliance performance. There appears to be a strong (not necessarily causal) relationship between the perception of cultural fit and the corresponding alliance performance. This finding may have important implications for alliance management. Instead of its general preoccupation with strategic and operational fit among alliance partners, more attention should be paid to cultural fit. The inclusion of cultural fit indicators in the overall partner selection process might well pay off in terms of increased alliance performance.

In Chapter 5, 'Cultural differences and homogeneity in strategic alliances: the case of Trimo Trebnje (Slovenia) and Trimo VSK (Russia)', Tekavčič, Dimovski, Peljhan and Škerlavaj pinpoint the issue of national, organizational and professional cultures within a strategic alliance. The study presents the case of Trimo Trebnje d.d., a Slovenian construction company, and its greenfield joint-venture investment Trimo VSK Kovrov from Russia. Using the Trompenaars measurement instrument they show that in terms of national cultures (as perceived by members of these two organizations) Slovenian and Russian companies differ significantly only in terms of in terms of specificity, achievement orientation and sequence. A relatively homogeneous organizational culture was developed and is still developing due to a strong training effect. Interactions among professional and national cultures prove that professional cultures have a bigger impact on employees' dedication than the organizational culture. They explain homogeneity in the manufacturing department in terms of the professional culture effect as well as good communication of values and practices in the past.

Chapter 6, 'Strategic importance of organizational culture in the context of organizational growth through acquisitions: the case of the Helios Group' by Zupan and Kaše, aims to analyse the cultural fit among 
the three largest companies in the Helios Group: the mother company Helios (Slovenian), and the acquired companies Zvezda Helios (Serbian) and Color (Slovenian as well) using the above-mentioned Trompenaars method. Cultural fit between the companies involved in an acquisition has been known to be one of the important factors determining the success of the acquisition. With the growing number of acquisitions, the Helios Group top management has also recognized this issue to be important for further development as a modern international corporation. They argue that companies should focus on the optimal cultural fit rather than absolute cultural fit. Some differences in organizational culture could be beneficial because they better suit either national (especially at lower firm levels) or professional cultures and could actually contribute positively to company performance. However, when it comes to lower firm levels, where the effect of national culture seems to be stronger, a careful consideration as to which organizational culture changes are really needed is crucial, because it would not be effective to go against national culture contexts or to break away too abruptly from traditions and thus risk a higher resistance to change.

Chapter 7, 'Cross-border marriages: Dutch-Japanese and DutchAmerican combinations' by Grotenhuis, deals with cultural differences within cross-border mergers. Several reasons for failure have been brought up in the literature; however real-life cases of the 'how' and 'why' are limited or fragmented, especially for processes of cultural integration. The cases described in this chapter concern combinations of Dutch-Japanese and Dutch-American organizations. Grotenhuis uses three in-depth case studies to illustrate cultural integration patterns. Based on these in-depth cases between Dutch-Japanese and Dutch-American mergers, and a literature review, he concludes that cultural differences can play a major role in the success of a merger, but not necessarily. This is related to several factors - amongst others, the degree of integration - but also to the way in which management deals with the differences. Based on the case studies, four different patterns of acculturation could be discerned: 'marriage after engagement', 'shotgun wedding', 'living apart together' and 'divorce'.

In Chapter 8, 'Managing potential conflicts in a European banking alliance in ICT: study of intro- and mutual perception combined for a cultural fit', Eppink, Ulijn and Van der Heijden go into some other factors that may impact upon the success of the strategic cooperation beside cultural (mis)fit. In this respect they draw attention to the appropriateness of the chosen aims for the alliance, the appropriateness of the chosen form relative to the aims, and the stages in the evolution of an alliance that may require adaptation of the alliance competences to the new situation. In the empirical part of the chapter, they investigate the role of culture in the strategic alliance within the Information and Communication Technology 
(ICT) area between seven European banks. Hall's (1995) cultural dimensions are used. They find that assertiveness and responsiveness play a major role, but uncertainty avoidance and power distance far less. Such factors have an impact on expectations for the cooperation, and also on the ways conflicts are resolved.

Chapter 9, 'Portrait of an odd-eyed cat: cultural crossing as a trademark for a Dutch-Thai strategic alliance' by Kwanjai and den Hertog, presents the case of a Dutch-Thai joint venture that thrived, by weaving together the many intricate cultural webs, to achieve a unique pattern of partnership which, metaphorically speaking, became its indispensible trademark. The case illustrates how the three levels of culture expounded in this book - national, organizational and professional cultures - could all interlace in a real-world setting and serve as an instrumental force of success amidst tension in one particular cross-border strategic alliance.

In Chapter 10, 'Resistance to the transfer of management knowledge in international ventures: steps towards a pathologic interpretation', Fink and Holden consider a longitudinal stylized case of Austrian firms taken over by a well-established and successful US firm with a clear and explicit corporate culture. After three to four years almost all original members had left the firm and were replaced by new ones who better fitted the corporate culture of the US firm. Why did a pattern like that emerge? Fink and Holden propose that it is not so much about differences in national culture, but a factor that is not necessarily visible and is almost certainly discounted until it is too late: psychological reactions to the disorienting impact of the change processes, which often are misinterpreted as staff resistance, but which are symptomatic of the very pathology of crosscultural business encounters. To support this proposition, they develop concepts of collective culture shock and cultural stretch. Their starting point is a consideration of four cases involving prominent organizations in their quest to find 'common cognitive ground' (Nonaka and Takeuchi, 1995) with protagonists in a variety of cross-cultural interactions, all of which have evolved over several years.

What are the outcomes of these chapters with regard to the relative impact of respectively national, corporate and professional culture on the performance of strategic alliances and M\&A? What progress could this book make, in following on from that by Cartwright and Cooper (1996) on the human factor in strategic alliances and M\&A? What research outcomes are to be expected, based upon some recommendations for future studies in this respect?

Increasingly it has been suggested in the literature that professional culture might easily overrule the effect of corporate culture or even national culture (Ulijn and Weggeman, 2001). For example, Sirmon and Lane (2004) 
argue that the level of culture that predicts individual behaviour most accurately is key to strategic alliance success. Leung et al. (2005) suggest that sources of self-identity like educational or professional affiliation may be more crucial in defining who people are, what motivates them and what they value as important than for national culture. According to Schultz (1998) the experiences of professionals of partnering organizations working together overshadow the differences in organizational and managerial preferences between the different organizations. This may imply that professional culture plays a very important role for successful cooperation.

The outcomes of the chapters of this book could not exactly confirm this. Although national culture and corporate culture received extensive attention, professional culture, however, gained remarkable interest from the authors: six out of the ten chapters include elements of it. For example, Walrave et al. (Chapter 3) investigated the parochial versus professional dimension as part of the corporate culture concept of Hofstede; Ulijn et al. (Chapter 4) added innovation drive as interaction between the professional culture of marketers and engineers and the organization-boundprofessional distinction between national culture and corporate culture; Tekavčič et al. (Chapter 5) were able to include differences among the departments of the investigated companies in the steel sector; Zupan and Kaše (Chapter 6) examined differences among the different departments within the acquiring and acquired firms in the painting business; Eppink et al. (Chapter 8) considered several sectors including the ICT banking sector; and finally Kwanjai and den Hertog (Chapter 9) investigated a Dutch-Thai case of a civil engineering alliance. In sum, this book covers a complete range of cultural levels involved in strategic alliances and M\&A. But a lot remains to be done.

Future studies on strategic alliances and M\&A should focus on all levels of cultural fit including professional culture, as has been argued in this book. Obviously, an important next step in this line of research would be the empirical testing of professional culture (and the relative importance of professional culture compared to national and organizational culture). A variety of different measures could be used to investigate professional culture, such as the different types of expertise among the professionals involved (see Van der Vegt and Bunderson, 2005) or, as suggested by Sirmon and Lane (2004), the form and duration of professional training, or the number of occupational memberships that the individuals gain.

Moreover, most scholars and practitioners intuitively feel that cultural differences matter in strategic alliances and $M \& A$, but when they matter, under what conditions they matter, and how they matter are at the moment poorly understood (Gibson et al., 2006; Stahl and Voigt, 2008; see also Grotenhuis, Chapter 7 in this book). Therefore, future research 
should pay attention to conditions that serve to moderate the cultureperformance relationship in strategic alliances and M\&A (Leung et al., 2005; Gibson et al., 2009). For example, the different forms of cooperation, namely strategic alliances and $\mathrm{M} \& \mathrm{~A}$, ranging from relatively high levels of integration to relatively low levels of integration, may have different consequences for culture. Cultural issues happen to be particularly relevant in M\&A of firms because different cultures must be integrated into a single one, or one culture has to be absorbed by the other (Pablo, 1994). Likewise, cultural conflicts are more ordinary in joint ventures, in which a closer contact between the partnering organizations is required, than in contractual alliances.

Also, researchers have paid relatively little attention to the process by which cultural differences affect the performance of firms engaging in strategic alliance or M\&A activity. More attention should be paid to micro behavioural processes (see Kumar and Das, Chapter 1 in this book) and opening up the black box of 'culture clash' (Li and Hambrick, 2005). Most research involving alliances and M\&A is at the firm or inter-firm level, while we know relatively little about behavioural issues such as decisionmaking, communication and conflict processing (Leung and White, 2005). Li and Hambrick (2005) emphasize that more attention should be paid to the small groups of people that implement the alliance, instead of purely concentrating on whether the two extensive entities are 'compatible'.

Indeed, analysts who attribute the failure of interorganizational collaborations or combinations (mergers, joint ventures, bilateral peacekeeping forces, interdepartmental task forces) to an amorphous 'culture clash' typically overlook the reality that collaborative efforts are played out in conference rooms, hallway conversations, e-mail exchanges, and phone calls in which small groups of people from two sides are trying to hammer out joint products. If enough of these small groups experience stereotyping, emotional conflict, and behavioral disintegration, then the overall collaborative enterprise is jeopardized. ( $\mathrm{Li}$ and Hambrick, 2005, 810)

Overall we feel this book contributes to our current knowledge about the relationship between external modes such as strategic alliances and M\&A and culture because we show that all levels of culture can have a strong effect on the performance of strategic alliances and M\&A. However, their specific effect is contextual and the levels seem to be interrelated strongly.

\section{ACKNOWLEDGEMENT}

The authors would like to thank Wim van Ravenswaaij, an industrial engineering MSc graduate from Eindhoven University of Technology, for his 
study on the impact of national, organizational and professional culture in $\mathrm{R} \& \mathrm{D}$ alliances.

\section{NOTES}

1. In cases of mergers and acquisitions, the formerly independent companies form a new legal entity. We speak of a merger when the companies are more or less equal. In an acquisition the larger or stronger company buys the smaller one. We define strategic alliances as a cooperation between two or more independent organizations to accomplish common and individual goals while keeping their own identity, including joint ventures.

2. Although we suggest that cultural differences play an important role for the success of alliances and M\&A, we are aware of the fact that numerous variables have been proposed to influence the success of strategic alliances and M\&A, cultural differences being only one of them.

3. This enumeration of variables regarding culture that has sought to explain the (under) performance of strategic alliances and M\&A is partly based on Stahl and Voigt (2008).

\section{REFERENCES}

Barkema, H.G., J.H. Bell and J.M. Pennings (1996), 'Foreign entry, cultural barriers, and learning', Strategic Management Journal, 17, 151-66.

Barkema, H.G. and F. Vermeulen (1997), 'What differences in the cultural backgrounds of partners are detrimental for international joint ventures?', Journal of International Business Studies, 28 (4), 845-64.

Birkinshaw, J., H. Bresman and L. Håkanson (2000), 'Managing the postacquisition integration process: how the human integration and task integration processes interact to foster value creation', Journal of Management Studies, 37, 395-425.

Brown, L., A. Rugman and A. Verbeke (1988), 'Japanese joint ventures with western multinationals: synthesizing the economic and cultural explanations of failure', Asia Pacific Journal of Management, 6, 225-42.

Calori, R., M. Lubatkin, P. Very and J.F. Veiga (1997), 'Administrative heritages: a historical institutional analysis of French and British firms', Organization Science, 8 (6), 681-96.

Cartwright, S. and C.L. Cooper (1993), 'The role of culture compatibility in successful organisation', The Academy of Management Executive, 34, 67-80.

Cartwright, S. and C.L. Cooper (1996), Managing Mergers, Acquisitions and Strategic Alliances: Integrating Peoples and Cultures, 2nd edn, Oxford: Butterworth-Heinemann.

Child, J. and D. Faulkner (1998), Strategies of Co-operation: Managing Alliances, Networks, and Joint Ventures, Oxford: Oxford University Press.

Datta, D.K. and G. Puia (1995), 'Cross-border acquisitions: an examination of the influence of relatedness and cultural fit on shareholder value creation in US acquiring firms', Management International Review, 35, 337-59.

Gibson, C.B., M.L. Maznevski and B.L. Kirkman (2009), 'When does culture matter', in R.S. Bhagat and R.M. Steers (eds), Cambridge Handbook of Culture Organizations, and Work, Cambridge: Cambridge University Press, pp. 46-68. 
Hall, Wendy (1995), Managing Cultures: Making Strategic Relationships Work, Chichester, UK and New York: Wiley.

Hambrick, D.C., J. Li, K. Xin and A.S. Tsui (2001), 'Compositional gaps and downward spiral in international joint venture management groups, Strategic Management Journal, 22, 1033-53.

Hofstede, G. (1980), Culture's Consequences: International Differences in WorkRelated Values, London: Sage Publications.

Hofstede, G. (2001), Culture's Consequences: Comparing Values, Behaviours, Institutions and Organizations across Nations, 3rd edn, London: Sage.

Hofstede, G., B. Neuijen, D.D. Ohayv and G. Sanders (1990), 'Measuring organizational cultures: a qualitative and quantitative study across twenty cases', Administrative Science Quarterly, 35, 286-316.

Kavanagh, M.H. and N.M. Ashkanasy (2006), 'The impact of leadership and change management strategy on organizational culture and individual acceptance of change during a merger', British Journal of Management, 17, 81-103.

Lajara, M.B., F.G. Lillo and V.F. Sempere (2003), 'Human resources management: a success and failure factor in strategic alliances', Employee Relations, 25 (1-2), 61-80.

Lane, P.J. and M. Lubatkin (1998), 'Relative absorptive capacity and interorganizational learning', Strategic Management Journal, 19 (5), 461-77.

Larsson, R. and S. Finkelstein (1999), 'Integrating strategic, organizational, and human resource perspectives on mergers and acquisitions: a case survey of synergy realization', Organization Science, 10, 1-27.

Larsson, R. and M. Lubatkin (2001), 'Achieving acculturation in mergers and acquisitions: an international case study', Human Relations, 54, 1573-1607.

Leung, K. and S. White (2005), 'Exploring dark corners: an agenda for organizational behavior research in alliance contexts', in O. Shenkar and J.J. Rever (eds), Handbook of Strategic Alliance, Thousand Oaks, CA: Sage, pp. 199-218.

Leung, K., R.S. Bhagat, N.R. Buchan, M. Erez and C.B. Gibson (2005), 'Culture and international business: recent advances and their implications for future research', Journal of International Business Studies, 36, 357-78.

Li, J. and D.C. Hambrick (2005), 'Factional groups: a new vantage on demographic faultlines, conflict and disintegration in work teams', Academy of Management Journal, 48 (5), 794-813.

Lyles, M.A. and J.E. Salk (1996) 'Knowledge acquisition from foreign parents in international joint ventures: an empirical examination in the Hungarian context', Journal of International Business Studies, 27 (5), 877-903.

Morosini, P., S. Shane and H. Singh (1998), 'National culture distance and crossborder acquisition performance', Journal of International Business Studies, 29 (1), 137-58.

Nahavandi, A. and A.R. Malekzadeh (1988), 'Acculturation in mergers and acquisitions', Academy of Management Review, 13, 79-90.

Nonaka, Ikujiro and Hirotaka Takeuchi (1995), The Knowledge-Creating Company, New York: Oxford University Press.

Olson, E.M., O.C. Walker Jr and R.W. Ruekert (1995), 'Organizing for effective new product development: the moderating role of product innovativeness', Journal of Marketing, 59 (1), 48-65.

Pablo, A.L. (1994), 'Determinants of acquisition integration level: a decisionmaking perspective', Academy of Management Journal, 37(4), 803-36.

Park, S.H. and G.R. Ungson (1997), 'Reexamining national culture, organizational 
complementarity and economic motivation on joint venture dissolution', Academy of Management Journal, 40 (2), 279-307.

Parkhe, A. (1991), 'Interfirm diversity, organizational learning and longevity in global strategic alliances', Journal of International Business Studies, 22 (4), 579-601.

Pothukuchi, V., F. Damanpour, J. Choi, C.C. Chen and S.H. Park (2002), 'National and organizational culture differences and international joint venture performance', Journal of International Business Studies, 33 (2), 243-65.

Salk, J.E. and O. Shenkar (2001), 'Social identities in an international joint venture: an exploratory case study', Organization Science, 12 (2), 161-78.

Sarkar, M.B., R. Echambadi, S.T. Cavusgil and P.S. Aulakh (2001), 'The influence of complementarity, compatibility, and relationship capital on alliance performance', Journal of Academy of Marketing Science, 29, 358-73.

Schneider, S.C. and A. De Meyer (1991), 'Interpreting and responding to strategic issues: the impact of national culture', Strategic Management Journal, 12, 307-20.

Schultz, M. (1998), 'European cultures in collaboration: do cultural differences matter?', in G. Sevón and K. Kreiner (eds), Constructing R\&D Collaboration: Lessons from European EUREKA Projects, Copenhagen: Copenhagen Business School Press, pp. 85-133.

Shenkar, O. (2001), 'Cultural distance revisited: towards a more rigorous conceptualization and measurement of cultural differences', Journal of International Business Studies, 32, 519-35.

Shenkar, O. and Y. Zeira (1992), 'Role conflict and role ambiquity of chief executive officers in international joint ventures', Journal of International Business Studies, 23 (1), 55-75.

Simonin, B.L. (1999), 'Ambiquity and the process of knowledge transfer in strategic alliances', Strategic Management Journal, 20, 595-623.

Sirmon, D.G. and P.J. Lane (2004), 'A model of cultural differences and international alliance performance', Journal of International Business Studies, 35, 306-19.

Stahl, G.K. and A. Voigt (2008), 'Do cultural differences matter in mergers and acquisitions? A tentative model and examination', Organization Science, 19 (1), 160-76.

Ulijn, J. and M. Weggeman (2001), 'Towards an innovation culture: what are its national, corporate, marketing and engineering aspects, some experimental evidence', in C. Cooper, S. Cartwright and C. Early (eds), Handbook of Organisational Culture and Climate, London: Wiley, pp. 487-517.

Van der Vegt, G.S. and J.S. Bunderson (2005), 'Learning and performance in multidisciplinary teams: the importance of collective team identification', Academy of Management Journal, 48 (3), 532-47.

Weber, Y., O. Shenkar and A. Raveh (1996), 'National and corporate cultural fit in mergers and acquisitions: an exploratory study', Management Science, 42, 1215-27.

Whitley, Richard D. (ed.) (1992), European Business Systems: Firms and Markets in their National Contexts, London: Sage. 